\title{
IMPROVING THE QUALITY OF TOURISM HUMAN RESOURCES IN THANH HOA PROVINCE IN THE CURRENT CONTEXT
}

\author{
MEJORA DE LA CALIDAD DE LOS RECURSOS HUMANOS DEL TURISMO EN LA \\ PROVINCIA DE THANH HOA EN EL CONTEXTO ACTUAL
}

Le Thanh Ha ${ }^{1}$; Vu Van Tuyen ${ }^{1}$; Ha Dinh Hung ${ }^{1}$; Doan Van Truong ${ }^{1 *}$ (D); Hoang Thi Hue ${ }^{1}$; Luu Thi Ngoc-Diep ${ }^{1}$.

1. Thanh Hoa University of Culture, Sports and Tourism, Vietnam.

*Corresponding author: D. Van Truong. e-mail: dvtruongxhh@gmail.com

\begin{abstract}
Thanh Hoa is aiming at developing tourism as a key economic industry in 2030, creating a motivation to impulse socio-economic development, making Thanh Hoa one of the top tourism development provinces of the country. With an aim to attract more domestic and international visitors, apart from improving quality and business environment, diversifying tourism products, Thanh Hoa needs to focus on training and capacity building for tourism human resources of the province. It requires a more professional tourism human resource that is equipped with essential skills to adapt and meet the demand of tourism development at the current period of time. Hence, this article analyses the real situation of tourism human resources in Thanh Hoa Province with a view to presenting relevant forecasts and recommendations on solutions in order to improve the quality of the tourism human resource of Thanh Hoa Province in the current context.
\end{abstract}

Keywords: tourism human resources; quality of the human resource; tourism development; Thanh Hoa tourism.

Cómo citar:

Thanh Ha, Le; Van Tuyen, Vu ; Dinh Hung, Ha ; Van Truong, Doan; Thi Hue, Hoang; Ngoc-Diep, Luu Thi. (2021). IMPROVING THE QUALITY OF TOURISM HUMAN RESOURCES IN THANH HOA PROVINCE IN THE CURRENT CONTEXT. Revista de Investigaciones Universidad del Quindio, 33(1), 196-205. https://doi.org/10.33975/riuq.vol33n1.557 


\section{RESUMEN}

Thanh Hoa tiene como objetivo desarrollar el turismo como una industria económica clave en 2030, creando una motivación para impulsar el desarrollo socioeconómico, lo que convierte a Thanh Hoa en una de las principales provincias de desarrollo turístico del país. Con el objetivo de atraer más visitantes nacionales e internacionales, además de mejorar la calidad y el entorno empresarial, diversificar los productos turísticos, Thanh Hoa debe centrarse en la formación y el desarrollo de capacidades para los recursos humanos turísticos de la provincia. Requiere un recurso humano turístico más profesional que esté equipado con las habilidades esenciales para adaptarse y satisfacer la demanda del desarrollo turístico en el período de tiempo actual. Por lo tanto, este artículo analiza la situación real de los recursos humanos turísticos en la provincia de Thanh Hoa con el fin de presentar pronósticos y recomendaciones relevantes sobre soluciones para mejorar la calidad del recurso humano turístico de la provincia de Thanh Hoa en el contexto actual.

Palabras clave: recursos humanos turísticos; calidad del recurso humano; desarrollo turístico; turismo de Thanh Hoa.

\section{INTRODUCTION}

Thanh Hoa is seen as a proud region with a long history and cultural traditions, as well as great tourism potentials based on the strength of natural resources anddiverse human ecology that are easy to create attractive and unique tourism products. Besides, it is impossible not to emphasize a favorable condition for tourism development, which is socio-economic development. ThanhHoais developing relatively quickly and stably, transforming the economic structure towards industry and services, in which tourism services play a significant role; People's life has been gradually improved; Infrastructure system has been increasingly invested and upgraded more synchronously and more modernly, etc. In addition, awareness of the role and position of tourism has been constantly raised; Party committees at all levels, local authorities have paid better attention and direction for tourism activities; the number of tourism businesses has increased, many tourism projects have been implemented, put into operation and served tourists; Tourism activities have attracted the attention of the residential community, etc.

However, it is impossible not to point out the basic difficulties that ThanhHoa tourism is facing such as inadequateinfrastructure, seasonality in exploitation, tourism resources diversified but not yet comprehensively planned, especially the quality of tourism human resources have not really met the development requirements. The contingent of state tourism management officials in most localities in the province remains thin, mainly concurrently holding multiple positions; Severalkey tourism localities do not have specialized tourism officials, resulting in limited management capacity. The human resources in tourism business establishments, especially small and medium-sized establishments, have not been given adequate attention, etc.These are major bottlenecks that are dragging down the development of the tourism industry.

The birth of Resolution No. $58^{1}$ brought both opportunities, but also posed great challenges in the development of the provincial tourism industry. The Resolution emphasizes that tourism development is a spearhead economic sector. With this orientation, it can be clearly seen that ThanhHoa has placed tourism in a central and important position. Therefore, in parallel with the priority of investment 1 Resolution No. 58-NQ/TW issued by the Politburo on August 5, 2020 "on the construction and development of ThanhHoa province by 2030 , with a vision to 2045 ". 
resources in infrastructure, technical materials of the tourism industry,developing tourist sites and products,marketing, strengthening tourism connections and links to expand the domestic tourist market towards the international tourist market, promoting the development of highquality professional tourism human resources should be one of the main focuses to be prioritized.

\section{CHARACTERISTICS \\ AND REQUIREMENTS OF TOURISM HUMAN RESOURCES IN THE CURRENT CONTEXT}

\section{Characteristics of tourism human resources classification}

The human resourcesof the tourism industry include the entire workforce that is directly and indirectly involved in the tourist service process. Therefore, when referring to the human resources of the tourism industry, it is not only about the professional workers serving tourists directly, but also the workers at the managerial level, training workers and others serving tourists indirectly. Accordingly, the tourism human resources are specifically classified as follows:

\section{- Group of tourism human resources in state managementagencies}

This group includes staff working in statetoursim management agencies from district units to local, regional and national tourism management boards. This group plays an important role in developing national and local tourism development strategies; consulting and planning tourism development policies; representing the State to guide, inspect and supervise tourism activities in general.

\section{- Group of tourism human resources in non- business units}

This group includes teachers, lecturers and researchers working in tourism-related research and training institutions. This is a section with high education qualifications and in-depth tourism knowledge; having the function of training and scientific research on tourism and playing a great role in the development of human resources in the tourism industry; researching strategies, advising on development policies that have a great impact on the quality and number of the tourism human resources and the tourism development orientation in the future. In addition, a small proportion of experts, trainers, assessors participate in domestic and international skills testing activities, join the council or jury of the examination centers to certify national vocational skills in the tourism sector.

\section{- Group of tourism human resources in business}

This is a group of human resources directly involved in and providing tourism services and products through business activities in the tourism sector. In general, this groupmakes up the majority of the total workforce and activities of the tourism industry. It is divided into three divisions with different levels and areas of expertise, including:

+Senior Business Management Division: This division includes the business leaders and the people in charge of the main business division in tourism businesses such as hotels, travel agencies and transporters, etc.

+ Divisiondirectly performing professional activities and providing tourism services: These are the employees directly involved in the process of providing services to meet the needs of tourists at tourism enterprises.

+ Functional and professional division to ensure business conditions of tourism enterprises:It includesthe employees in functional departments such as finance-accounting; materials and equipment, general administration; human resources, etc. [1]. 
Requirements for training and developing tourism human resources in the current context

- Train and develop in sufficient number to ensure adequate supply for all levels of state management, non-business units and tourism enterprises. The preparation of a sufficient structure for the number of managerial workers to professional workers will meet the entire operating system from policy development, planning, state management, research and training organizations to tourism business activities in the direction of synchronization and quality assurance.

- Ensure that the industry structure is consistent with the requirements of employers and tourism businesses. This is a content that plays a particularly important role in training and developing human resources.

- Ensure the professional quality and professionalism in providing services. In fact, the number of human resources may be sufficient, but the quality of professional expertise determines the quality of all stages of tourism activities from state management, research, training and service business activities of enterprises.

- Form the style, dedication, and sensitivity in providing tourism services. The above service delivery and supply process is really sensitive, because tourists may be vulnerable to unsatisfying demand in the consumption process. Therefore, service staff, in addition to meeting the professional requirements, should form career sensitivity in providing travel services, thereby shaping their dedicated style.

\section{REALITY OF TOURISM HUMAN RESOURCESINTHANHHOAPROVINCE}

\section{Actual situation of tourism human resources in ThanhHoa province}

- In terms of number:The entire tourism industry in ThanhHoa province achieved the number of direct tourism workers of 20,800 and 40,600 people in 2016 and 2020, respectively, increasing nearly $200 \%$ compared to 2016. This shows that the tourism human resources inThanhHoa province is developing strongly in number.

However, there are also considerable disparities in tourism among areas, regions and localities in the province; accordingly, the workforce is mainly concentrated in coastal areas, big cities, and key tourist areas of the province such as Sam Son, HaiTien, and ThanhHoa city, etc; the tourism workforce in ethnic minority and mountainous and rural areas remains really modest.

- In terms of quality: The qualification of tourism workers has also increased sharply and has become more and more quality. According to the Report of ThanhHoa Department of Culture, Sports and Tourism, the whole province had about 40,600 tourism workers in 2020. The number of trained and retrained workers is 32,200 people, in which employees with higher education qualification or higher are 4,000 people; 12,900 people with college and intermediate qualifications; 15,400 people trained and fostered. However, the number of untrained tourism workers also accounts for a large number, encompassing 5,390 and 8,300 people in 2016 and 2020, respectively, accounting for $20 \%$. The lack of professional knowledge, weak skills and no language proficiencyof untrained workers have a great impact on the quality of tourism services as well as the image of the business establishments in the province.

\section{- In terms of tourism human resources} training: The training and development of tourism human resources in ThanhHoaprovince have been interested and developed for recent years. The whole province currently has 4 tourism-oriented and tourism training institutions, including 02 universities (ThanhHoa University of Culture, Sports and Tourism and Hong Duc University), and 01 college (College of Economic and Technical Industry and Trade) and 01 intermediate school [Vocational College of Trade and Tourism].The training capacity 
of the tourism training institutions has been gradually improved. Facilities, teaching and learning equipment have been upgraded thanks to investment from the province, ministries and departments. For ThanhHoa University of Culture, Sports and Tourism, it is now training 03 university-level majors, including Tourism, Travel and Travel Services Administration and Hospitality Management. In addition, it also organizes training courses and certifies professional tourism guidance and tourism operations according to the regulations of the General Department of Tourism. Hong Duc University offers university-level training in Tourism and Vietnam Studies (Orientation for Hotel and Restaurant Management). The College of Economic and Technical Industry and Trade and the Vocational School of Trade and Tourism are training a number of professions such as hotels, restaurants, travel, tour guides, food processing, etc. at college, intermediate levels. Accordingly, the training institutions in the province are gradually improving the training quality of tourism human resources to meet the current requirements. However, the reality shows that a large part of tourism students who have college and university qualifications must be trained again after graduation. Although they have professional knowledge and skills, they also limit skills of communication, handling situations, especially language skills.

On the other hand, every year, ThanhHoaDepartment of Culture, Sports and Tourism regularly presides over and coordinates with the People's Committees of districts, towns and cities to organize courses of training and fostering tourism expertise for managers and staff in tourism businesses to improve the quality of tourism human resources. Thereby, the number and quality of tourism human resources in ThanhHoa province has significantly increased for recent years.

Table 1. Qualification structure of tourism human resources inThanhHoa province in the 2016-2020 period Unit:

people

\begin{tabular}{|c|c|c|c|c|c|}
\hline \multirow{2}{*}{ Year } & Quantity & $\begin{array}{c}\text { University or } \\
\text { higher }\end{array}$ & $\begin{array}{c}\text { College, } \\
\text { intermediate }\end{array}$ & $\begin{array}{c}\text { Vocational } \\
\text { training, on- } \\
\text { site training }\end{array}$ & Untrained \\
\hline 2016 & 20,800 & 1,730 & 5,480 & 8,200 & 5,390 \\
\hline 2017 & 24,300 & 2,070 & 6,690 & 9,550 & 5,990 \\
\hline 2018 & 28,400 & 2,500 & 8,000 & 11,000 & 6,900 \\
\hline 2019 & 33,500 & 3,150 & 10,200 & 13,050 & 7,100 \\
\hline 2020 & 40,600 & 4,000 & 12,900 & 15,400 & 8,300 \\
\hline
\end{tabular}

Source: ThanhHoa Department of Culture, Sports and Tourism

In general, the human resources operating in the tourism sector in the province today have made obvious changes, innovating, improving professional qualifications, gradually meeting the requirements of tourism business activities in accordance with the market mechanism. Currently, more and more businesses are applying advanced human resources management models, doing well in the stages of recruitment, training, retraining and use of human resources. In particular, the large tourism enterprises have trainedthe human resources who arefairly qualified, well-trained, formal, conscious, serious, professional, knowledgeable, skilled, meeting the requirements of the job.

\section{Forecasting the demand for tourism human resources in ThanhHoa province}

The provincial tourism development strategy by 2025, with a vision to 2030 has identified tourism development towards professionalism, modernity and focus; attaching importance to diversifying and developing tourism products with potentials and advantages in order to improve the efficiency of tourism investment and exploitation and 
affirm brand and competitiveness. Striving to 2030, ThanhHoa will become one of the tourism development centers of the North Central region and the whole country, in which tourism will be a spearhead economic sector with professionalism, comprehending relatively synchronous and modern facilities; diversified high-quality tourism products branded with bold national cultural identity. Total tourists will reach 16.5 million people, including 500 thousand international tourists, earning 64,600 billion VND, creating jobs for about 60,300 people ${ }^{2}$.

To accomplish that goal, the provincial tourism industry has been implementing many solutions, in which training to improve the quality of human resources is the top factor. Accordingly, in the coming time, the province will spend certain resources from the state budget to organize the implementation, at the same time, the socialization of training has also been promoted, focusing on training professional and vocational skills and foreign languages, in the direction of new training and fostering.

Looking at the overall picture of ThanhHoa tourism manpower for recent years, although there has been a significant change in both number and quality, it is not really commensurate with the inherent potential and speed as well as strong development of ThanhHoa tourism. Currently, the human resources of the tourism industry are growing larger and more powerful, but still havethe following limitations and shortcomings:

- The quality of the tourism workforce in some places is still low, the professional qualifications and foreign languages have not met the increasing requirements of the job.

- In fact, a few tourism workers are trained and

2 Tourism development strategy of ThanhHoa province by 2025 , with a vision to 2030 , issued according to Decision No. 492/QD-UBND by the People's Committee of ThanhHoa province on February 9, 2015. qualified, whilea large number of workersare untrained.

- There is a lack of foreign investment and international cooperation in the training and development of human resources in the tourism industry of the province.

- Local people's awareness of tourism development is not high, because people think that tourism is not stable, and strong investment in tourism will disrupt the natural landscape, pollute the environment.

Accordingly, with the human resource reality of ThanhHoa province and the provincial tourism development policy in the coming time, the demand for tourism human resources by 2030 should be comprehensively developed in both scale and structure across all entities opertingin the industry.

\section{PROPOSING ANUMBER OFSOLUTIONS TO IMPROVE THE QUALITY OF TOURISM HUMAN RESOURCES IN THANHHOA PROVINCE IN THE CURRENT PERIOD}

\section{Proposed orientation perspectives}

- It is necessary to improve the capacity to promote, cooperate and attract resources inside and outside the province, especially from the private sector to develop tourism, thereby developing human resources in the tourism industry. State tourism managers of the province should take responsibility for career orientation, demand forecasting, and encouraging and promoting the socialization of human resource training and development in the tourism industry. Officers at tourism training institutions and vocational schools should design and provide training products in association with the needs and characteristics of ThanhHoa province. Tourism business units actively participate in the network to create resources, train and retrain 
human resources in the tourism industry.

- Renovate the working mechanism of the state tourism management agency in a flexible direction, closely linked to the market, and external partners to actively respond to changes and demands from outside, at the same time attract resources to improve efficiency to support the development of the tourism industry and tourism human resources in the locality.

- Renovate training and fostering activities in both public and private sectors to equip new capacities in accordance with market requirements, industry development trends and especially the demand for developing the products of particular strengths in ThanhHoa province.

- Increase the attraction of high-quality human resources from home and abroad to address immediate needs. For the purpose of improving the quality of tourism human resources in the coming time, the key tasks are given as standardization and development, so the province needs human resources who are capable of consulting, designing, training and transferring training technology. In the coming period, the labor market in the ASEAN region will be opened up, in which skilled tourism workers may freely move between ASEAN countries. That is an opportunity for ThanhHoa province. Our province shoulddevelop mechanisms and policies as soon as possible, and identify the needs and objects to take the initiative in promoting and attracting.

\section{Specific recommendations}

In the context of increasingly crowded numbers of domestic and international tourists coming to ThanhHoa, in addition to investing in the development of infrastructure, technical facilities, unique and quality tourism products and types to attract tourists, training, developing and improving the quality of human resources for tourism are the top important factors. Therefore, ThanhHoa should focus on doing well the following measures to develop the human resources of the tourism industry:

\section{On the side of the state tourism management} agency: It is necessary to review and survey the quality of tourism human resources in the province to serve as a basis for the statistics and development of training, retraining and fostering long-term tourism human resources according to the progress for each period or development stage of the industry, in which priority should be given to fostering professional skills, cultural behavior and foreign languages. It also shouldregularly organize refresher courses to improve professional skills for tourism human resources; increase investment and mobilize all resources to organize training courses to raise awareness for sustainable tourism development, responsible tourism, foreign language skills, qualification and professionalism of the contingent of State management officials, tourism business establishments and population communities; send officials and specialists to participate in domestic and foreign tourism management courses; regularly organize training courses on management knowledge and tourism business culture for all tourism workers in the area, etc.

\section{On the side of the tourism businesses:}

Firstly, regularly organize refresher courses, update knowledge and skills for employees. From the reality of staff capacity, each tourism business should coordinate with tourism training institutions in the province to organize refresher courses updating necessary knowledge and skills for employees. Employees should be funded to participate in training programs to improve qualifications and degrees. For several reputable tourism groups and businesses in the province, it is possible to propose building models of training and retraining centers to provide tourism human resources such as FLC, Sao Mai, Da Lan Groups, etc.

Secondly, the business should be flexible in transferring and creating suitable jobs for the 
employees to be replaced by smart equipment and machines. In addition, it should pay attention to retrain and improve the skills and professional knowledge of this team so that they are able to work in other stages of their profession, avoiding unemployment when there is a replacement with modern machines. .

Thirdly, the business should be active in associating with tourism training institutions. It should create favorable conditions in terms of facilities for students to visit and practice. Experts should be sent to guide students and traininstitutions to share practical experiences so that students can learn and improve their knowledge and skills before graduation.

Fourthly, the tourism businessshould focus on policies to attract talented people to supplement available resources and develop business in the direction of technology application. In order to attract and retain talents, it should offer attractive incentive packages, benefits and salaries to attract outside resources to work; coordinate recruitment at universities and training centers to find qualified candidates who are willing to learn; carefully screenthe input labor source to make sure that the recruited employees are truly capable, devoted to work, enthusiastic and creative, and tend to work in a long-term period.

- For local people:Strengthen propaganda and education activities to raise awareness of each citizen about the characteristics of the tourism industry, emphasize the advantages (opportunities to communicate widely and access culturesof many countries, the work is not monotonous, etc.); clearly indicate the difficulties and challenges of the profession (working on days, off hours, intensity of work, etc.); At the same time, it is necessary to promote propaganda to raise awareness of the community and sectors and levels about the role and position of tourism in the province's socio-economic development so that everyone can respond and participate responsibly in local tourism activities.

\section{On the side of the training institutions:}

Firstly, develop a standard program framework in accordance with the demand of tourism businesses in the current period. Moreover, on October 20, 2017, the Ministry of Education and Training issued Official Letter 4929/BGDDTGDDH on the application of a specific mechanism for training the tourism industry. Accordingly, it is necessary to increase the time for practical training and internship in enterprises. Training institutions should autonomously choose partner enterprises; take responsibility for checking the quality assurance conditions and training capacity of partner enterprises in the process of training and organizing for students to practice and take internship. Therefore, tourism training institutions in the province should coordinate with tourism businesses to rebuild the program framework and output standards towards training to meet social needs.

In addition, increase the length of the IT modules, especially the subjects that update the development trend of world tourism such as smart tourism, information technology application in tourism, etc. Accordingly, training institutions should exploit and apply software for managing tourism, hotel and travel businesses in the teaching process for students.

Secondly, improve the capacity of the faculty

Lecturers should improve their knowledge by themselves in many ways such as self-study, taking short and long-term courses in tourism profession, taking courses for technicians, trainers and auditors according to the VTOS standard; continue to study at higher levels of education. In particular, each year, the lecturers shouldspend a certain amount of time to survey and research reality at centers, routes, sites, resorts, travel businesses, hotels - restaurants to improve their knowledge, professional capacity, grasp the trend of tourism development to apply in teaching. Besides, for the purpose of integrating internationally, in the coming time, lecturers 
specializing in tourism should improve their foreign language proficiency so that they can both teach in Vietnamese and in English to meet theintegration needs.

\section{Thirdly, perfect tourist practice facilities}

Training institutions should increasingly invest in and upgrade the technical facilities of existing tourist practice rooms to meet the standards for students to have a good practice environment; connect with business establishments outside the society, especially 4-5 star hotels at home and abroad to create conditions for students to have the opportunity to experience while studying at the school.

In addition, the training institutions should equip management software, apply smart technology in teaching specialized subjects. To implement this solution, each subsector shouldlink up with businesses to be allowed to equip the same software for businesses, helping learners quickly catch up with practical learning, take internship and work after graduation.

Fourthly, link training with tourism businesses Strengthen connection with domestic and foreign tourism businesses to send students for practice and internships. In these units, students will have the opportunity to exchange, approach reality, learn about the establishments' organization and business operations, apply the knowledge learned at the school to specific jobs, and formcommunication skills with customers, with colleagues, and accumulate experience.

The school and businesses should coordinate to organize tourism seminars, customer conferences, invite tourism experts and facilities using the school's tourism human resources to participate in evaluating the training results of the school. On the basis of the fact, find a better training direction. Moreover, after graduating from university, students have the opportunity to work in enterprises which they took internships.

\section{Policy recommendations}

Firstly, promote the application of advanced science and technology to research and statistics for the training and fostering of tourism human resources in the province. Strengthen the work of statistics and scientific research for tourism human resource development in the province; invest in material foundations andapplied equipment, efficiently exploit information technology to promote the tourism human resource training inThanhHoa province; establish and operate the database on tourism human resources in the province. Develop and disseminate online training programs in the provincial tourism sector based on the promulgated sets of national occupational skill standards.

Secondly, encourage the creation of sustainable connections, cooperation for mutual development among the components of a "Ecosystem of innovation, creativity and entrepreneurship", encompassing tourism training institutions in the province, tourism business communityin the province, state management agencies, research and development organizations; promote innovation and startups to improve the competitiveness of tourism training institutions in the province in accordance with the $4^{\text {th }}$ Industrial Revolution.

Thirdly, strengthen tripartite cooperation in the development of tourism human resources in the province; mobilize and efficiently utilize domestic and foreign resources for tourism human resource training and development. Encourage tourism training institutions and tourism-related research institutions to set up production and service establishments; promote the role and enhance the responsibility of tourism businesses in training activities; facilitate all sectors of the society to participate in the development of tourism human resources; increase the attraction of foreign capital and advanced technologies to serve the development of tourism human resources. 


\section{CONCLUSION}

ThanhHoa has many advantages to develop tourism, being a tourist destination not only for domestic tourists but also for foreign visitors. For recent years,the tourism industry in ThanhHoa province has seen remarkable growth, enhancing the role and position of tourism in socio-economic development of the whole province. Accordingly, for the purpose of making ThanhHoa become one of the tourism development centers of the
North Central region and the whole country, in which tourism is a spearhead economic sector with professionalism, the development of human resources is the deciding factor. Above, the author proposes a number of solutions to improve the quality of human resources in ThanhHoa province with the aim of contributing to tourism development in ThanhHoa province commensurate with the inherent potentials and in line with the social development trend in the current period.

\section{REFERENCES}

1. Ministry of Culture, Sports and Tourism (2016), Project "Enhancing social demand-oriented training in the tourism sector up to 2025 ".

2. Le Thanh Ha (2019), Research on improving specialized English proficiency for a team of tour guides and speakers in ThanhHoa province, Provincial scientific topic (2017-2019).

3. PhD. Nguyen Van Luu (2013), Development of tourism human resources - a decisive factor for sustainable tourism development, Culture and Information Publishing House.

4. Resolution No. 58-NQ/TW enacted by the Politburo on August 5, 2020"on the construction and development of ThanhHoa province by 2030, with a vision to 2045"

5. Decision No. 290/QD-TU issued by Thanh Hoa Provincial Party Committee on May 27, 2016 on promulgating the ThanhHoa Tourism Development Program for the 2016-2020 period.

6. Decision No. 3173/QD-UBND issued by the People's Committee of ThanhHoa province on September 11, 2013 onapproving the project "Improving the quality of tour guides and speakers in ThanhHoa province"

7. Decision No.1358/QD-UBND issued by the People's Committee of ThanhHoa province on April 27,2017 on approving the project "Developing training programs to improve the quality of tourism business administration according to international standard model for the 2017-2020 period".

8. Decision No. 492/QD-UBND issued bythe People's Committee of ThanhHoa provinceon February 9, 2015 on approving the "Strategy for tourism development in Thanh Hoa province by 2025, vision to 2030 ". 